\title{
Simultaneous quantitative analysis of olmesartan, amlodipine and hydrochlorothiazide in their combined dosage form utilizing classical and alternating least squares based chemometric methods
}

\author{
HANY W. DARWISH ${ }^{1,2 *}$ \\ AHMED H. BAKHEIT ${ }^{1}$ \\ ALI S. ABDELHAMEED ${ }^{1}$ \\ ${ }^{1}$ Department of Pharmaceutical \\ Chemistry, College of Pharmacy \\ King Saud University, P.O. Box 2457 \\ Riyadh 11451, Saudi Arabia \\ ${ }^{2}$ Department of Analytical Chemistry \\ Faculty of Pharmacy, Cairo University \\ Cairo, Egypt
}

\begin{abstract}
Simultaneous spectrophotometric analysis of a multi-component dosage form of olmesartan, amlodipine and hydrochlorothiazide used for the treatment of hypertension has been carried out using various chemometric methods. Multivariate calibration methods include classical least squares (CLS) executed by net analyte processing (NAP-CLS), orthogonal signal correction (OSC-CLS) and direct orthogonal signal correction (DOSC-CLS) in addition to multivariate curve resolution-alternating least squares (MCR-ALS). Results demonstrated the efficiency of the proposed methods as quantitative tools of analysis as well as their qualitative capability. The three analytes were determined precisely using the aforementioned methods in an external data set and in a dosage form after optimization of experimental conditions. Finally, the efficiency of the models was validated via comparison with the partial least squares (PLS) method in terms of accuracy and precision.
\end{abstract}

Keywords: multivariate calibration methods, olmesartan medoxomil, amlodipine besylate, hydrochlorothiazide, spectrophotometry, pharmaceutical tablets
Accepted September 23, 2015

Online published January 8, 2016 
ing (NAP-CLS), orthogonal signal correction (OSC-CLS) and direct orthogonal signal correction (DOSC-CLS). These three pre-processing techniques are applied to improve the predictability of the CLS model. This improvement could increase the application of the CLS model in quantitative analysis by taking advantage of its inherent qualitative properties.

The four developed methods were applied to analyze a ternary mixture of olmesartan medoxomil (OLM), amlodipine besylate (AML) and hydrochlorothiazide (HCT). Olmesartan medoxomil (Fig. 1) is a powerful and selective angiotensin AT1 receptor blocker (7), amlodipine besylate is a calcium channel blocker used for the management of hypertension and angina pectoris (8) and hydrochlorothiazide is a benzothiadiazine diuretic that blocks $\mathrm{NaCl}$ transport in distal convoluted tubule (9). This ternary mixture (OLM, AML and HCT) is available in the markets as a tablet dosage form (Tribenzor ${ }^{\circledR}$ tablets) in several different dosages. Few methods are available for simultaneous analysis of this ternary mixture. According to extensive literature review, the reported methods for analysis of this mixture include high performance liquid chromatography (HPLC) (10-12), spectrophotometry (13-16) and chemometric methods $(16,17)$. Chemometric methods that were used for spectrophotometric data in previous work were CLS, PCR and partial least squares (PLS) (17) and artificial neural network (ANN) (16). In the work of Darwish et al. (17) on the same drug mixture the predictability of CLS method was found to be low. This finding motivated us to further extend our work and to investigate the quantitative power of other methods as compared to PLS.

FDA approved Tribenzor ${ }^{\circledR}$ tablets in four ratios. All the reported methods were developed for the analysis of only one ratio for this combination (4:1:2.5). Hence, this study was designed to achieve a number of goals. Firstly, to develop simple, robust and accurate chemometric methods for the simultaneous determination of OLM, AML and HCT in Tribenzor ${ }^{\circledR}$ tablets in all FDA approved ratios; secondly, to show the quantitative power as well as qualitative power of the proposed methods. Thirdly, to show the effect of different preprocessing procedures, such as NAP, OSC and DOSC, on the performance of CLS in quantitative analysis, since other chemometric approaches designed only for quantitative analysis [e.g., multiple linear regression (MLR) and locally weighted regression (LWR) were not applied in this study].

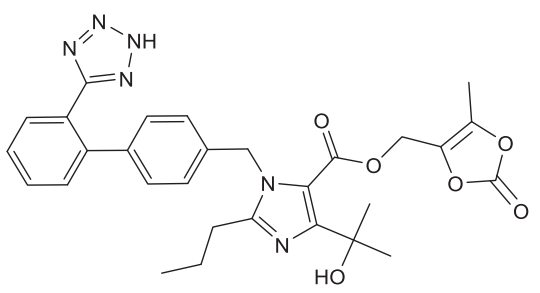

Olmesartan medoxomil (OML)

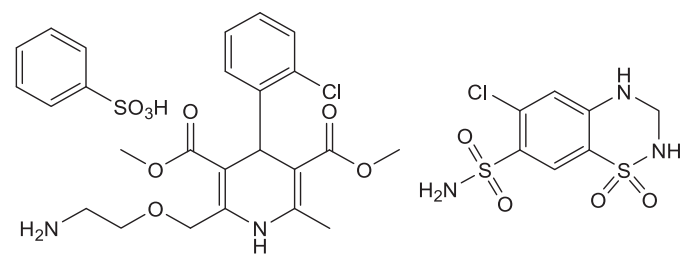

Amlodipine besylate (AML) Hydrochlorothiazide (HCT)

Fig. 1. Chemical structures of olmesartan medoxomil (OLM), amlodipine besylate (AML) and hydrochlorothiazide (HCT). 


\section{EXPERIMENTAL}

\section{Apparatus}

A double-beam UV-visible spectrophotometer (Shimadzu, Japan) model UV-1650 PC, with a quartz cuvette cell of 1-cm path length, was connected to an IBM-compatible computer. The spectral bandwidth was $2 \mathrm{~nm}$ and wavelength-scanning speed $2800 \mathrm{~nm} \mathrm{~min}^{-1}$. A UV lamp with a short wavelength $(254 \mathrm{~nm})$ was used. All recorded spectra were converted to the ASCII format by the UV-probe personal spectroscopy software version 2.21 (Shimadzu).

\section{Materials}

OLM was acquired from AK Scientific Inc. (USA), HCT from Al-Hekma Pharmaceutical Company (Egypt) and AML was kindly supplied by Pfizer Inc. (USA). The purities of OLM, AML and HCT were 99.5, 99.5 and $99.78 \%$, respectively. Tribenzor ${ }^{\circledR}$ tablet is available in several different strength combinations including, 40/10/25 mg, 40/10/12.5 mg, $40 / 5 / 25 \mathrm{mg}$ and $40 / 5 / 12.5 \mathrm{mg}$ of OLM, AML base (10 $\mathrm{mg}$ or $5 \mathrm{mg}$ of AML base equivalent to $13.9 \mathrm{mg}$ or $6.95 \mathrm{mg}$ of AML besylate) and HCT, respectively. Tribenzor ${ }^{\circledR}$ tablets were procured from Daiichi Sankyo Inc., USA). Acetonitrile used throughout this study was of spectroscopic grade (Sigma-Aldrich Chemie GmbH, Germany).

\section{Preparation of OLM, AML and HCT standard solutions}

Stock solutions of OLM $\left(250 \mu \mathrm{g} \mathrm{mL}^{-1}\right)$, AML $\left(200 \mu \mathrm{g} \mathrm{mL} \mathrm{L}^{-1}\right)$ and HCT $\left(250 \mu \mathrm{g} \mathrm{mL}^{-1}\right)$ were prepared in acetonitrile. All stock solutions were stored at $4{ }^{\circ} \mathrm{C}$ until analysis.

\section{Preparation of pharmaceutical tablet sample solutions}

Seven tablets of each Tribenzor ${ }^{\circledR}$ formulation were weighed and the average tablet mass was calculated. Tablets were crushed to a fine powder, and a quantity of powdered tablets, equivalent to the mass of one tablet was extracted with $80 \mathrm{~mL}$ acetonitrile with the help of sonication for $30 \mathrm{~min}$ and diluted up to $100 \mathrm{~mL}$ with acetonitrile. The extracts were filtered through a $0.45-\mu \mathrm{m}$ MF-Millipore membrane filter (composed of mixed cellulose esters) and the first portion of each filtrate was discarded. The filtrates were then diluted with the same solvent and subjected to analysis by the developed method.

\section{Chemometric procedures and softwares}

Principles and theoretical background of the chemometric methods are detailed in the literature for the MCR-ALS method $(2,18,19)$, CLS model (20) and different pre-processing techniques (NAP, OSC and DOSC) (21-25).

MCR-ALS, NAP-CLS and OSC-CLS methods were implemented in Matlab ${ }^{\circledR}$ 7.1.0.246 (R14) using MCR-ALS (26) and MVC1 toolboxes (27).

Multi-level, multi-factor calibration design (28) was used for construction of 25 mixture samples by transferring different volumes of OLM, AML and HCT from their stan- 
H. W. Darwish et al.: Simultaneous quantitative analysis of olmesartan, amlodipine and hydrochlorothiazide in their combined dosage form utilizing classical and alternating least squares based chemometric methods, Acta Pharm. 66 (2016) 83-95.

Table I. The 5-level 3-factor experimental design of the calibration and validation set mixtures ${ }^{a}$

\begin{tabular}{cccccccc}
\hline Mix & OLM & AML & HCT & Mix & OLM & AML & HCT \\
\hline 1 & 20.00 & 5 & 12.50 & 14 & 20.00 & 7 & 15.00 \\
2 & 20.00 & 3 & 10.00 & 15 & 25.00 & 7 & 10.00 \\
3 & 15.00 & 3 & 15.00 & 16 & 25.00 & 3 & 13.75 \\
4 & 15.00 & 7 & 11.25 & 17 & 15.00 & 6 & 10.00 \\
5 & 25.00 & 4 & 15.00 & 18 & 22.50 & 3 & 12.50 \\
6 & 17.50 & 7 & 12.50 & 19 & 15.00 & 5 & 13.75 \\
7 & 25.00 & 5 & 11.25 & 20 & 20.00 & 6 & 13.75 \\
8 & 20.00 & 4 & 11.25 & 21 & 22.50 & 6 & 11.25 \\
9 & 17.50 & 4 & 13.75 & 22 & 22.50 & 4 & 10.00 \\
10 & 17.50 & 6 & 15.00 & 23 & 17.50 & 3 & 11.25 \\
11 & 22.50 & 7 & 13.75 & 24 & 15.00 & 4 & 12.50 \\
12 & 25.00 & 6 & 12.50 & 25 & 17.50 & 5 & 10.00 \\
13 & 22.50 & 5 & 15.00 & & & & \\
\hline
\end{tabular}

${ }^{a}$ Concentrations of mixture components in $\mu \mathrm{g} \mathrm{mL}^{-1}$.

dard stock solutions into 5-mL measuring flasks. Dilution of these solutions was done with acetonitrile and mixed well (Table I). Fifteen of the above-mentioned 25 samples were used to construct chemometric models (calibration set) and 10 samples were used as a validation set to test the predictive power of the developed models. For the different ratios of three analytes in Tribenzor ${ }^{\circledR}$ tablets, each analyte concentration range was dependent on the

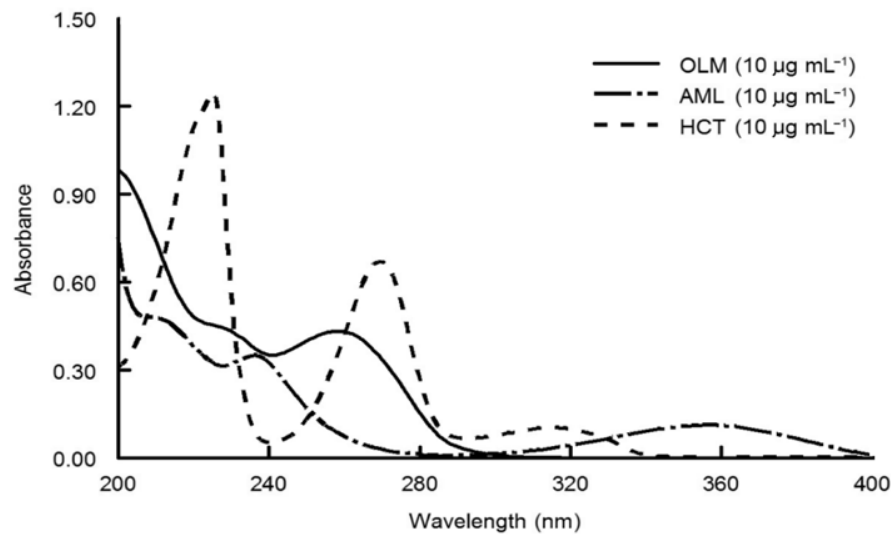

Fig. 2. Absorption spectra for OLM, AML and HCT against acetonitrile as a blank (10 $\mu \mathrm{g} \mathrm{mL}^{-1}$ each). 


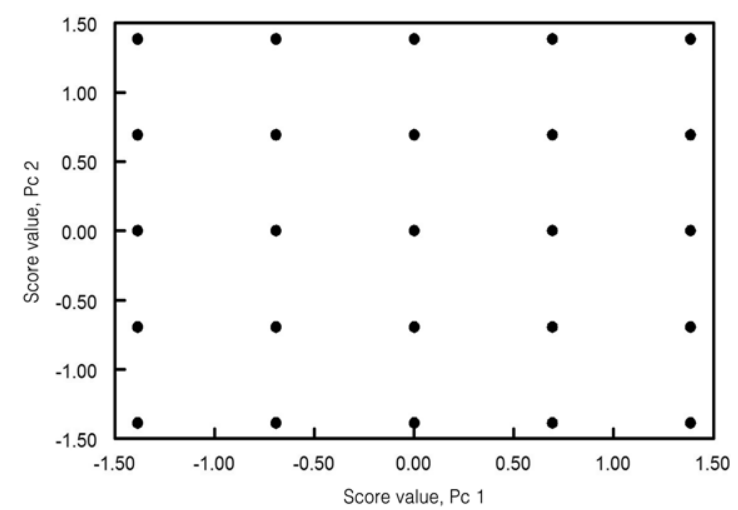

Fig. 3. Score plot for the mean centred 25 samples concentration matrix of the five level three component experimental design. PC 1, 2 - first, second principal component.

calibration range of each analyte in 25 samples. UV spectra of all the 25 samples were obtained from 200 to $400 \mathrm{~nm}$ against solvent blank and subject to Matlab for calculations. The noisy region (200-230 $\mathrm{nm}$ ) and the zero absorbance of OLM and HCT after $340 \mathrm{~nm}$ explained the rejection of these parts from the spectra (Fig. 2).

A plot of the 2D scores for the first two PCs of the concentration matrix confirmed the position of the samples in space, orthogonality, rotatability and symmetry (28) as anticipated in Fig. 3. Mean centering of the data showed to be the best pre-processing procedure for getting the best results in case of improved CLS methods.

Optimization of the number of factors for the NAP-CLS, OSC-CLS and DOSC CLS models. - Leave-one-out (LOO) CV was used in our study for optimizing the number of factors for building the investigated methods (20), by building the model using the $I-1$ sample set (calibration set consisting of 14 samples) to predict the one sample left (validation sample). The root mean square error of CV (RMSECV) was calculated as

$$
R M S E C V=\sqrt{\frac{1}{\mathrm{I}} \sum_{i=1}^{\mathrm{I}}\left(c_{\mathrm{i}}-\hat{c}_{\mathrm{i}_{-} \mathrm{Cv}}^{\mathrm{A}}\right)^{2}}
$$

where $I$ is the number of objects in the calibration set, $c_{\mathrm{i}}$ is the known concentration for sample $i$ and $\hat{c}_{\mathrm{i} \text { cv }}^{\mathrm{A}}$ is the predicted concentration of sample $i$ using $A$ components. Mean centering was applied on the calibration set each time successive samples were left out.

Root mean square of calibration (RMSEC), root mean square of prediction (RMSEP) were calculated in the same manner for the calibration and validation set, respectively, according to the following equation

$$
R M S E C P=\sqrt{\frac{1}{\mathrm{I}} \sum_{i=1}^{\mathrm{I}}\left(c_{\mathrm{i}}-\hat{c}_{\mathrm{i}}^{\mathrm{A}}\right)^{2}}
$$



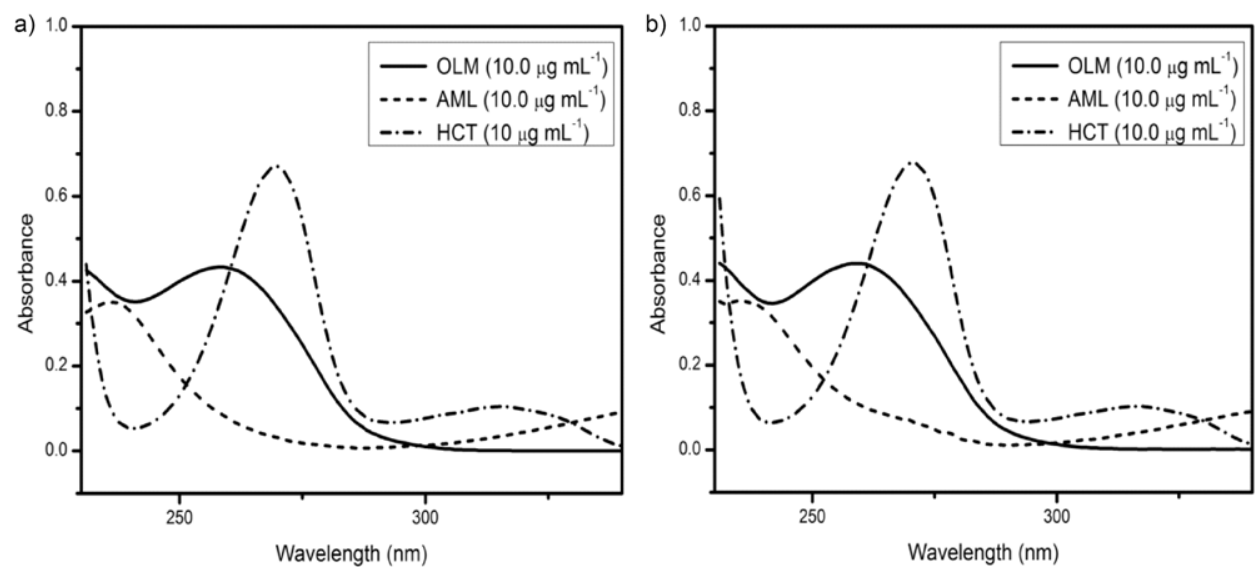

Fig. 4. Estimated absorption spectra by: a) MCR-ALS and b) true spectra, of OLM, AML and HCT against acetonitrile.

where $I$ is the number of samples in the calibration (in case of RMSEC) or validation set (in case of $R M S E P), c_{\mathrm{i}}$ is the known concentration for sample $i$ and $\hat{c}_{\mathrm{i}}^{\mathrm{A}}$ is the estimated concentration of sample $i$ using $A$ components. RMSEC gives an idea about the quality of the developed models while RMSEP shows the prediction power of the developed models.

\section{RESULTS AND DISCUSSION}

\section{MCR-ALS method}

MCR-ALS method is supposed to provide an ideal estimation of the concentration and spectra profiles of the three analytes OLM, AML and HCT. First, the model was applied on the calibration set (15 samples). Non-negativity constraint was applied for both concentration and spectral data. The pronounced resemblance between the estimated pure spectra of OLM, AML and HCT and the true ones (Fig. 4) assured the performance of the model to predict pure spectra for the three components in the analyzed mixture. Evolving factor analysis (EFA) was used to predict the concentration profiles of the three components.

Values of the lack of fitness (lof), percent of variance and standard deviation of the residuals with respect to the experimental data were $0.10889,99.999 \%$ and 0.00089 , respectively, at iteration number 13 . These values indicate the high quality of the model.

\section{Improved CLS models}

For proper construction of NAP-CLS, OSC-CLS and DOSC-CLS models, the number of projection matrix factors (NAP-CLS) and the number of extracted factors (OSC-CLS and DOSC-CLS) should be optimized. For this reason, CV was applied where log PRESS (predicted residual error sum of squares) values were calculated. The optimal number of fac- 
H. W. Darwish et al.: Simultaneous quantitative analysis of olmesartan, amlodipine and hydrochlorothiazide in their combined dosage form utilizing classical and alternating least squares based chemometric methods, Acta Pharm. 66 (2016) 83-95.

Table II. Prediction of the calibration set by MCR-ALS and improved-CLS methods

\begin{tabular}{|c|c|c|c|c|c|c|c|c|}
\hline \multicolumn{3}{|c|}{ Method } & \multicolumn{3}{|c|}{ MCR-ALS } & \multicolumn{3}{|c|}{ NAP-CLS } \\
\hline OLM & AML & $\mathrm{HCT}$ & OLM & AML & $\mathrm{HCT}$ & OLM & AML & $\mathrm{HCT}$ \\
\hline \multicolumn{3}{|c|}{ True $\left(\mu \mathrm{g} \mathrm{mL}^{-1}\right)$} & Recovery (\%) & Recovery (\%) & Recovery (\%) & Recovery (\%) & Recovery (\%) & Recovery (\%) \\
\hline 25 & 7 & 10 & 98.92 & 99.29 & 99.40 & 99.32 & 99.14 & 100.20 \\
\hline 15 & 3 & 15 & 98.27 & 100.00 & 99.27 & 98.33 & 100.00 & 99.20 \\
\hline 15 & 4 & 12.5 & 99.20 & 101.25 & 100.72 & 98.67 & 101.25 & 100.24 \\
\hline 15 & 5 & 13.75 & 100.13 & 99.20 & 100.58 & 99.93 & 99.20 & 100.65 \\
\hline 15 & 6 & 10 & 100.67 & 99.17 & 99.80 & 99.47 & 99.17 & 98.70 \\
\hline 15 & 7 & 11.25 & 100.13 & 99.71 & 100.36 & 99.33 & 99.57 & 99.91 \\
\hline 17.5 & 3 & 11.25 & 100.97 & 101.67 & 101.16 & 100.69 & 101.67 & 100.44 \\
\hline 17.5 & 7 & 12.5 & 100.91 & 100.57 & 101.28 & 100.97 & 100.71 & 101.68 \\
\hline 17.5 & 4 & 13.75 & 101.89 & 99.25 & 100.51 & 102.17 & 99.25 & 100.73 \\
\hline 17.5 & 5 & 10 & 101.83 & 102.40 & 101.30 & 101.31 & 102.20 & 100.50 \\
\hline 17.5 & 6 & 15 & 99.60 & 98.00 & 99.87 & 100.11 & 98.17 & 100.53 \\
\hline 20 & 5 & 12.5 & 99.70 & 94.40 & 98.08 & 100.00 & 94.40 & 98.32 \\
\hline 20 & 3 & 10 & 99.65 & 99.33 & 100.80 & 99.45 & 99.33 & 99.90 \\
\hline 20 & 4 & 11.25 & 101.10 & 101.00 & 100.44 & 101.20 & 100.75 & 100.27 \\
\hline 20 & 6 & 13.75 & 98.25 & 105.33 & 97.96 & 98.75 & 105.33 & 98.69 \\
\hline \multicolumn{3}{|c|}{ Mean (\%) } & 100.08 & 100.04 & 100.10 & 99.98 & 100.01 & 100.00 \\
\hline \multicolumn{3}{|c|}{ SD } & 1.15 & 2.36 & 1.05 & 1.10 & 2.34 & 0.1 \\
\hline \multicolumn{3}{|c|}{$R M S E C\left(\mu \mathrm{g} \mathrm{mL}^{-1}\right)$} & 0.2026 & 0.1227 & 0.1270 & 0.1863 & 0.1220 & 0.1107 \\
\hline & & & \multicolumn{3}{|c|}{ OSC-CLS } & \multicolumn{3}{|c|}{ DOSC-CLS } \\
\hline OLM & AML & $\mathrm{HCT}$ & OLM & AML & HCT & OLM & AML & HCT \\
\hline \multicolumn{3}{|c|}{ True $\left(\mu \mathrm{g} \mathrm{mL} L^{-1}\right)$} & Recovery (\%) & Recovery (\%) & Recovery (\%) & Recovery (\%) & Recovery (\%) & Recovery (\%) \\
\hline 25 & 7 & 10 & 99.40 & 99.43 & 100.20 & 99.40 & 99.43 & 100.20 \\
\hline 15 & 3 & 15 & 98.20 & 99.67 & 99.20 & 98.20 & 100.00 & 99.27 \\
\hline 15 & 4 & 12.5 & 98.60 & 101.00 & 100.24 & 98.60 & 101.00 & 100.24 \\
\hline 15 & 5 & 13.75 & 100.00 & 99.20 & 100.51 & 100.00 & 99.20 & 100.58 \\
\hline 15 & 6 & 10 & 99.60 & 99.00 & 98.60 & 99.53 & 99.00 & 98.60 \\
\hline 15 & 7 & 11.25 & 99.53 & 99.57 & 99.73 & 99.53 & 99.57 & 99.82 \\
\hline 17.5 & 3 & 11.25 & 100.46 & 101.67 & 100.62 & 100.51 & 101.67 & 100.53 \\
\hline 17.5 & 7 & 12.5 & 101.20 & 100.71 & 101.60 & 101.20 & 100.71 & 101.60 \\
\hline 17.5 & 4 & 13.75 & 102.11 & 99.250 & 100.73 & 102.11 & 99.25 & 100.73 \\
\hline 17.5 & 5 & 10 & 101.26 & 102.20 & 100.50 & 101.26 & 102.20 & 100.50 \\
\hline 17.5 & 6 & 15 & 100.29 & 98.17 & 100.40 & 100.23 & 98.17 & 100.53 \\
\hline 20 & 5 & 12.5 & 99.95 & 94.40 & 98.32 & 99.95 & 94.40 & 98.32 \\
\hline 20 & 3 & 10 & 99.20 & 99.33 & 100.20 & 99.25 & 99.33 & 100.10 \\
\hline 20 & 4 & 11.25 & 101.10 & 101.00 & 100.44 & 101.10 & 101.00 & 100.36 \\
\hline 20 & 6 & 13.75 & 98.90 & 105.50 & 98.62 & 98.85 & 105.50 & 98.69 \\
\hline \multicolumn{3}{|c|}{ Mean (\%) } & 99.99 & 100.01 & 99.99 & 99.98 & 100.03 & 100.00 \\
\hline \multicolumn{3}{|c|}{ SD } & 1.095 & 2.366 & 0.921 & 1.061 & 2.364 & 0.908 \\
\hline \multicolumn{3}{|c|}{ RMSEC $\left(\mu \mathrm{g} \mathrm{mL}^{-1}\right)$} & 0.1842 & 0.1235 & 0.1111 & 0.1848 & 0.1235 & 0.1097 \\
\hline
\end{tabular}

RMSEC - root mean square error of calibration. 
tors was selected according to Haaland and Thomas (29). Two factors were required for building improved CLS models for the three analytes except in the case of OSC-CLS for HCT where three factors were required. This fact shows that NAP, as a pre-processing technique, is simpler than OSC, especially in the case of HCT, even when the prediction ability of the CLS model is not enhanced.

After parameters optimization and the calibration step, all models were applied successfully for estimation of OLM, AML and HCT in calibration (Table II) and in validation

Table III. Prediction of the independent validation test set by the proposed MCR-ALS and improved CLS methods

\begin{tabular}{|c|c|c|c|c|c|c|c|c|}
\hline & & & \multicolumn{3}{|c|}{ MCR-ALS } & \multicolumn{3}{|c|}{ NAP-CLS } \\
\hline OLM & AML & HCT & OLM & AML & HCT & OLM & AML & HCT \\
\hline \multicolumn{3}{|c|}{ True $\left(\mu \mathrm{g} \mathrm{mL} L^{-1}\right)$} & Recovery (\%) & Recovery (\%) & Recovery (\%) & Recovery (\%) & Recovery (\%) & Recovery (\%) \\
\hline 20 & 7 & 15 & 100.75 & 99.86 & 99.00 & 101.60 & 100.00 & 100.07 \\
\hline 22.5 & 3 & 12.5 & 100.40 & 100.67 & 102.08 & 101.07 & 100.67 & 102.56 \\
\hline 22.5 & 4 & 10 & 101.16 & 102.50 & 100.40 & 101.38 & 102.25 & 100.30 \\
\hline 22.5 & 5 & 15 & 100.62 & 99.00 & 98.73 & 101.64 & 99.20 & 99.80 \\
\hline 22.5 & 6 & 11.25 & 99.64 & 99.00 & 97.42 & 100.00 & 99.00 & 97.87 \\
\hline 22.5 & 7 & 13.75 & 100.93 & 99.57 & 94.91 & 101.69 & 99.71 & 96.00 \\
\hline 25 & 3 & 13.75 & 100.16 & 95.33 & 98.98 & 101.16 & 95.33 & 99.85 \\
\hline 25 & 4 & 15 & 99.88 & 96.00 & 96.20 & 101.04 & 96.25 & 97.40 \\
\hline 25 & 5 & 11.25 & 99.36 & 97.60 & 97.07 & 99.96 & 97.40 & 97.60 \\
\hline 25 & 6 & 12.5 & 99.04 & 96.83 & 101.12 & 99.88 & 97.00 & 102.24 \\
\hline \multicolumn{3}{|c|}{ Mean $(\%)$} & 100.19 & 98.64 & 98.59 & 100.94 & 98.68 & 99.37 \\
\hline \multicolumn{3}{|c|}{ SD } & 0.67 & 2.21 & 2.24 & 0.73 & 2.15 & 2.13 \\
\hline \multicolumn{3}{|c|}{$R M S E P\left(\mu \mathrm{g} \mathrm{mL}^{-1}\right)$} & 0.1594 & 0.1064 & 0.3428 & 0.2627 & 0.1027 & 0.2771 \\
\hline & & & \multicolumn{3}{|c|}{ OSC-CLS } & \multicolumn{3}{|c|}{ DOSC-CLS } \\
\hline OLM & AML & $\mathrm{HCT}$ & OLM & AML & $\mathrm{HCT}$ & OLM & AML & HCT \\
\hline \multicolumn{3}{|c|}{ True $\left(\mu \mathrm{g} \mathrm{mL}^{-1}\right)$} & Recovery (\%) & Recovery (\%) & Recovery (\%) & Recovery (\%) & Recovery (\%) & Recovery (\%) \\
\hline 20 & 7 & 15 & 101.85 & 100.00 & 100.00 & 101.80 & 100.00 & 100.07 \\
\hline 22.5 & 3 & 12.5 & 100.89 & 101.00 & 102.72 & 100.93 & 101.00 & 102.64 \\
\hline 22.5 & 4 & 10 & 101.24 & 102.50 & 100.50 & 101.24 & 102.50 & 100.30 \\
\hline 22.5 & 5 & 15 & 101.69 & 99.20 & 99.80 & 101.69 & 99.20 & 99.87 \\
\hline 22.5 & 6 & 11.25 & 100.00 & 99.17 & 97.96 & 100.00 & 99.17 & 97.87 \\
\hline 22.5 & 7 & 13.75 & 101.87 & 99.71 & 95.93 & 101.82 & 99.71 & 96.00 \\
\hline 25 & 3 & 13.75 & 101.00 & 96.00 & 100.07 & 101.04 & 95.67 & 99.93 \\
\hline 25 & 4 & 15 & 100.96 & 96.50 & 97.47 & 100.96 & 96.50 & 97.47 \\
\hline 25 & 5 & 11.25 & 99.88 & 97.80 & 97.87 & 99.88 & 97.80 & 97.69 \\
\hline 25 & 6 & 12.5 & 99.96 & 97.17 & 102.32 & 99.92 & 97.17 & 102.32 \\
\hline \multicolumn{3}{|c|}{ Mean (\%) } & 100.93 & 98.91 & 99.46 & 100.93 & 98.87 & 99.42 \\
\hline \multicolumn{3}{|c|}{ SD } & 0.77 & 2.05 & 2.16 & 0.76 & 2.10 & 2.14 \\
\hline \multicolumn{3}{|c|}{$R M S E P\left(\mu \mathrm{g} \mathrm{mL}^{-1}\right)$} & 0.2641 & 0.0950 & 0.2776 & 0.2627 & 0.0963 & 0.2768 \\
\hline
\end{tabular}

RMSEP - root mean square error of prediction. 
sets (Table III). The mean recovery, standard deviation, RMSEC, RMSEP values are summarized in Tables II and III. The law values of RMSEP indicate the minor error of prediction and the high predictive ability of the developed methods.

The suggested methods were then applied with a great success to the analysis of Tribenzor $^{\circledR}$ tablets in all FDA approved ratios (Table IV). This fact was further assessed by the statistical comparison of $t$ - and $F$-values of the suggested models and the reference PLS method (17) (Table V), showing that there was no significant difference between our models and the reference in either accuracy or precision.

\section{Figures of merit}

Figures of merit were calculated by the MVC1 toolbox for NAP-CLS, OSC-CLS and DOSC-CLS models. The results for the suggested models for the three drugs are presented in Table VI. The best figures of merit were obtained from the application of the DOSC-CLS model. This is indicated by the high sensitivity and selectivity and low values of $L O D$. This may be attributed to the highest capability of DOSC-CLS to extract the noise from the spectral data.

Table IV. Analysis results for the prediction of the dosage form by the proposed MCR-ALS and improved-CLS methods

\begin{tabular}{|c|c|c|c|c|c|c|c|c|c|c|c|}
\hline \multicolumn{6}{|c|}{ Dosage form } & \multicolumn{3}{|c|}{ MCR-ALS } & \multicolumn{3}{|c|}{ NAP-CLS } \\
\hline \multicolumn{3}{|c|}{ Ratio } & \multicolumn{3}{|c|}{ Label claim $\left(\mu \mathrm{g} \mathrm{mL}^{-1}\right)$} & \multirow{2}{*}{$\begin{array}{c}\text { OLM } \\
\% \text { of the } \\
\text { label claim }\end{array}$} & \multirow[t]{2}{*}{ AML } & \multirow[t]{2}{*}{ HCT } & \multirow[t]{2}{*}{ OLM } & \multirow[t]{2}{*}{ AML } & \multirow[t]{2}{*}{ HCT } \\
\hline OLM & AML & $\mathrm{HCT}$ & OLM & AML & $\mathrm{HCT}$ & & & & & & \\
\hline 4 & 1 & 2.5 & 20 & 6.95 & 12.5 & 97.48 & 98.48 & 97.79 & 97.53 & 98.68 & 98.04 \\
\hline 4 & 1 & 1.25 & 30 & 10.42 & 9.375 & 102.61 & 97.75 & 96.42 & 103.41 & 101.54 & 98.60 \\
\hline 8 & 1 & 5 & 30 & 5.21 & 18.75 & 101.73 & 98.11 & 99.87 & 103.77 & 96.73 & 102.22 \\
\hline 8 & 1 & 2.5 & 30 & 5.21 & 9.375 & 101.34 & 96.09 & 99.59 & 102.14 & 98.85 & 100.69 \\
\hline \multicolumn{6}{|c|}{ Mean (\%) } & 100.79 & 97.61 & 98.42 & 101.72 & 98.95 & 99.89 \\
\hline \multicolumn{6}{|c|}{ SD } & 2.27 & 1.06 & 1.62 & 2.88 & 1.98 & 1.93 \\
\hline \multicolumn{6}{|c|}{ Dosage form } & \multicolumn{3}{|c|}{ OSC-CLS } & \multicolumn{3}{|c|}{ DOSC-CLS } \\
\hline \multicolumn{3}{|c|}{ Ratio } & \multicolumn{3}{|c|}{ Label claim $\left(\mu \mathrm{g} \mathrm{mL}^{-1}\right)$} & OLM & AML & $\mathrm{HCT}$ & OLM & AML & $\mathrm{HCT}$ \\
\hline OLM & AML & $\mathrm{HCT}$ & OLM & AML & $\mathrm{HCT}$ & $\begin{array}{c}\% \text { of the } \\
\text { label claim }\end{array}$ & & & & & \\
\hline 4 & 1 & 2.5 & 20 & 6.95 & 12.5 & 97.43 & 98.01 & 97.97 & 97.39 & 98.48 & 97.86 \\
\hline 4 & 1 & 1.25 & 30 & 10.42 & 9.375 & 102.07 & 98.91 & 98.63 & 102.09 & 98.71 & 98.6 \\
\hline 8 & 1 & 5 & 30 & 5.21 & 18.75 & 103.63 & 96.48 & 102.24 & 103.62 & 96.38 & 102.29 \\
\hline 8 & 1 & 2.5 & 30 & 5.21 & 9.375 & 103.84 & 98.58 & 101.19 & 103.83 & 98.58 & 100.69 \\
\hline \multicolumn{6}{|c|}{ Mean (\%) } & 101.74 & 98.00 & 100.01 & 101.73 & 98.04 & 99.86 \\
\hline \multicolumn{6}{|c|}{ SD } & 2.98 & 1.08 & 2.04 & 3.00 & 1.11 & 2.02 \\
\hline
\end{tabular}


H. W. Darwish et al.: Simultaneous quantitative analysis of olmesartan, amlodipine and hydrochlorothiazide in their combined dosage form utilizing classical and alternating least squares based chemometric methods, Acta Pharm. 66 (2016) 83-95.

Table V. Statistical comparison of the results obtained by MCR-ALS and improved CLS methods and the reference PLS method for the analysis of Tribenzor ${ }^{\circledR}$ tablets

\begin{tabular}{|c|c|c|c|c|c|c|c|c|c|}
\hline \multirow{2}{*}{ Parameter } & \multicolumn{3}{|c|}{ MCR-ALS } & \multicolumn{3}{|c|}{ NAP-CLS } & \multicolumn{3}{|c|}{ Reference method (ref. 17) } \\
\hline & OLM & AML & HCT & OLM & AML & HCT & OLM & AML & HCT \\
\hline \multirow{4}{*}{$\begin{array}{l}\% \text { of } \\
\text { label claim }\end{array}$} & 97.48 & 98.48 & 97.79 & 97.53 & 98.68 & 98.04 & 103.48 & 97.6 & 98.6 \\
\hline & 102.61 & 97.75 & 96.42 & 103.41 & 101.54 & 98.60 & 103.66 & 98.86 & 102.23 \\
\hline & 101.73 & 98.11 & 99.87 & 103.77 & 96.73 & 102.22 & 101.88 & 96.51 & 101.09 \\
\hline & 101.34 & 96.09 & 99.59 & 102.14 & 98.85 & 100.69 & 97.29 & 97.38 & 97.94 \\
\hline Mean (\%) & 100.79 & 97.61 & 98.42 & 101.72 & 98.95 & 99.89 & 101.58 & 97.59 & 99.97 \\
\hline $\mathrm{SD}$ & 2.270 & 1.055 & 1.619 & 2.877 & 1.976 & 1.928 & 2.968 & 0.97 & 2.03 \\
\hline Variance & 5.153 & 1.113 & 2.621 & 8.277 & 3.905 & 3.718 & 8.809 & 0.941 & 4.121 \\
\hline $\begin{array}{l}\text { Number of } \\
\text { samples }\end{array}$ & 4 & 4 & 4 & 4 & 4 & 4 & 4 & 4 & 4 \\
\hline Student's $t^{\mathrm{a}}$ & 0.422 & 0.028 & 1.192 & 0.067 & 1.238 & 0.055 & - & - & - \\
\hline \multirow[t]{4}{*}{$F$ ratio $^{\mathrm{a}}$} & 1.710 & 1.182 & 1.192 & 1.064 & 4.151 & 1.108 & - & - & - \\
\hline & \multicolumn{3}{|c|}{ OSC-CLS } & \multicolumn{3}{|c|}{ DOSC-CLS } & \multicolumn{3}{|c|}{ Reference method (ref. 17) } \\
\hline & OLM & AML & HCT & OLM & AML & HCT & OLM & AML & HCT \\
\hline & 102.07 & 98.01 & 97.97 & 97.39 & 98.48 & 97.86 & 103.48 & 97.60 & 98.60 \\
\hline \multirow{3}{*}{$\begin{array}{l}\% \text { of } \\
\text { label claim }\end{array}$} & 97.428 & 98.91 & 98.63 & 102.09 & 98.71 & 98.60 & 103.66 & 98.86 & 102.23 \\
\hline & 103.63 & 96.48 & 102.24 & 103.62 & 96.38 & 102.29 & 101.88 & 96.51 & 101.09 \\
\hline & 103.84 & 98.58 & 101.19 & 103.83 & 98.58 & 100.69 & 97.29 & 97.38 & 97.94 \\
\hline Mean (\%) & 101.74 & 98.00 & 100.01 & 101.73 & 98.04 & 99.86 & 101.58 & 97.59 & 99.97 \\
\hline SD & 2.982 & 1.076 & 2.036 & 2.997 & 1.109 & 2.015 & 2.968 & 0.97 & 2.03 \\
\hline Variance & 8.895 & 1.158 & 4.144 & 8.982 & 1.230 & 4.060 & 8.809 & 0.941 & 4.121 \\
\hline $\begin{array}{l}\text { Number of } \\
\text { samples }\end{array}$ & 4 & 4 & 4 & 4 & 4 & 4 & 4 & 4 & 4 \\
\hline Student's $t^{\mathrm{a}}$ & 0.078 & 0.562 & 0.030 & 0.073 & 0.611 & 0.070 & - & - & - \\
\hline$F$ ratio $^{\mathrm{a}}$ & 1.01 & 1.231 & 1.006 & 1.02 & 1.307 & 1.015 & - & - & - \\
\hline
\end{tabular}

${ }^{\text {a }}$ For $p=0.05$ and 6 degrees of freedom tabular cries $t$ and $F$ are 2.447 and 9.277, respectively.

Our work provides the first spectrophotometric method designed for the analysis of Tribenzor tablets in all FDA approved ratios. In addition, other reported spectrophotometric methods (13-15) experienced low robustness since they are considered as univariate calibration methods (calibration relies on measuring absorbances at just one wavelength). Thus, any error in the wavelength scale will prompt false results. Incorporation of numerous spectral wavelengths instead of utilizing a solitary wavelength enhances enormously the precision and predictive power of the multivariate calibration methods. 
H. W. Darwish et al.: Simultaneous quantitative analysis of olmesartan, amlodipine and hydrochlorothiazide in their combined dosage form utilizing classical and alternating least squares based chemometric methods, Acta Pharm. 66 (2016) 83-95.

Table VI. Figures of merit of OLM, AML and HCT for improved CLS methods

\begin{tabular}{|c|c|c|c|c|}
\hline Component & Figure of merit & NAP-CLS & OSC-CLS & DOSC-CLS \\
\hline \multirow[t]{4}{*}{ OLM } & Sensitivity $\left(\mathrm{mL} \mu \mathrm{g}^{-1}\right)^{\mathrm{a}}$ & 0.089 & 0.091 & 0.22 \\
\hline & Analytical sensitivity $\left(\mathrm{mL} \mu \mathrm{g}^{-1}\right)^{\mathrm{b}}$ & 78 & 80 & 190 \\
\hline & Selectivity ${ }^{c}$ & 0.4 & 0.41 & 1 \\
\hline & $L O D\left(\mu \mathrm{g} \mathrm{mL}^{-1}\right)^{\mathrm{d}}$ & 0.037 & 0.036 & 0.015 \\
\hline \multirow[t]{4}{*}{ AML } & Sensitivity $\left(\mathrm{mL} \mu \mathrm{g}^{-1}\right)^{\mathrm{a}}$ & 0.074 & 0.074 & 0.2 \\
\hline & Analytical sensitivity $\left(\mathrm{mL} \mu \mathrm{g}^{-1}\right)^{\mathrm{b}}$ & 65 & 65 & 180 \\
\hline & Selectivity ${ }^{c}$ & 0.36 & 0.37 & 0.99 \\
\hline & $L O D\left(\mu \mathrm{g} \mathrm{mL}^{-1}\right)^{\mathrm{d}}$ & 0.045 & 0.045 & 0.017 \\
\hline \multirow[t]{4}{*}{ HCT } & Sensitivity $\left(\mathrm{mL} \mu \mathrm{g}^{-1}\right)^{\mathrm{a}}$ & 0.15 & 0.15 & 0.19 \\
\hline & Analytical sensitivity $\left(\mathrm{mL} \mu \mathrm{g}^{-1}\right)^{\mathrm{b}}$ & 130 & 130 & 170 \\
\hline & Selectivity ${ }^{c}$ & 0.79 & 0.8 & 1 \\
\hline & $L O D\left(\mu \mathrm{g} \mathrm{mL}^{-1}\right)^{\mathrm{d}}$ & 0.022 & 0.022 & 0.017 \\
\hline
\end{tabular}

All the methods were built by 2 factors except OSC-CLS model, which was built by 3 factors for HCT.

${ }^{a}$ Calibration sensitivity measures the changes in response as a function of the concentration of a particular analyte.

${ }^{\mathrm{b}}$ Analytical sensitivity equals sensitivity divided by instrumental noise.

c Selectivity indicates the part of the total signal that is not lost due to spectral overlap.

${ }^{\mathrm{d}}$ Limit of detection is the lowest concentration of an analyte that can be detected, but not necessarily quantified.

\section{CONCLUSIONS}

Different chemometric models have been applied for the analysis of OLM, AML and HCT in their combined dosage form. The methods are: MCR-ALS, NAP-CLS, OSC-CLS and DOSC-CLS methods. These methods have the qualitative power (estimation of pure spectra) as well as quantitative power (prediction of concentrations of the three analytes in their mixtures). The developed methods are more rapid and easier compared to the traditional spectrometric methods along with other important analytical merits such as sensitivity and selectivity. Among the proposed pre-processing steps, DOSC was the most powerful one, increasing the quantitative power of the CLS method. All the suggested methods were validated and can be applied for routine quality control analysis of Tribenzor ${ }^{\circledR}$ tablets in all FDA approved ratios without prior separation or interference from commonly encountered additives.

Acronyms. - AML - amlodipine besylate, ANN - artificial neural network, CLS - classical least squares, DOSC - direct orthogonal signal correction, HCT - hydrochlorothiazide, LWR - locally weighted regression, MCR-ALS - multivariate curve resolution-alternating least squares, MLR - multiple linear regression, NAP - net analyte processing, OLM - olmesartan medoxomil, OSC - orthogonal signal correction, PCR - principal component regression, PLS - partial least squares. 
Acknowledgements. - The authors extend their sincere appreciation to the Deanship of Scientific Research at King Saud University for its funding of this research through the Research Group Project no. RGP-VPP-322.

\section{REFERENCES}

1. T. Sharma, N. Mishra, S. C. Si and D. G. Shankar, Simultaneous estimation of olmesartan medoxomil and amlodipine besylate in solid dosage form by UV spectrophotometry, Pharm. Lett. 2 (2010) 302-307.

2. M. Mirzaei, M. Khayat and A. Saeidi, Determination of para-aminobenzoic acid (PABA) in Bcomplex tablets using the Multivariate Curve Resolution-Alternating Least Squares (MCR-ALS) method, Sci. Iran. 19 (2012) 561-564; DOI: 10.1016/j.scient.2011.12.016.

3. E. Peré-Trepat, S. Lacorte and R. Tauler, Alternative calibration approaches for LC-MS quantitative determination of coeluted compounds in complex environmental mixtures using multivariate curve resolution, Anal. Chim. Acta 595 (2007) 228-237; DOI: 10.1016/j.aca.2007.04.011.

4. T. Azzouz and R. Tauler, Application of multivariate curve resolution alternating least squares (MCR-ALS) to the quantitative analysis of pharmaceutical and agricultural samples, Talanta 74 (2008) 1201-1210; DOI: 10.1016/j.talanta.2007.08.024.

5. M. Antunes, J. Simao, A. Duarte and R. Tauler, Multivariate curve resolution of overlapping voltammetric peaks: quantitative analysis of binary and quaternary metal mixtures, Analyst $\mathbf{1 2 7}$ (2002) 809-817; DOI: 10.1039/B200243B.

6. H. Winning, F. H. Larsen, R. Bro and S. B. Engelsen, Quantitative analysis of NMR spectra with chemometrics, J. Magn. Reson. 190 (2008) 26-32; DOI: 10.1016/j.jmr.2007.10.005.

7. K. Koga, S. Yamagishi, M. Takeuchi, Y. Inagaki, S. Amano, T. Okamoto, T. Saga, Z. Makita and M. Yoshizuka, CS-886, a new angiotensin II type 1 receptor antagonist, ameliorates glomerular anionic site loss and prevents progression of diabetic nephropathy in Otsuka Long-Evans Tokushima fatty rats, Mol. Med. 8 (2002) 591-599.

8. Martindale - The Complete Drug Reference“ (Ed. S. C. Sweetman), 36 ed., The Pharmaceutical Press, London 2009.

9. R. F. Reilly and E. K. Jackson, Regulation of Renal Function and Vascular Volume, in Goodman and Gilman's The Pharmacological Basis of Therapeutics (Eds. L. L. Brunton, B. A. Chabner and B. C. Knollmann) McGraw Hill, New York 2010.

10. A. Pawar, A. N. Rao, J. S. Rao and V. J. Rao, A validated method for the simultaneous quantification of hydrochlorothiazide, olmesartan medoxomil and amlodipine in bulk and pharmaceutical dosage form, J. Pharm. Res. 5 (2012) 43-46.

11. K. K. Kumar, C. K. Rao, G. Madhusudan and K. Mukkanti, Rapid simultaneous determination of olmesartan-amlodipine and hydrochlorothiazide in combined pharmaceutical dosage form by stability-indicating ultra performance liquid chromatography, Am. J. Anal. Chem. 3 (2012) 50-58; DOI: 10.4236/ajac.2012.31008.

12. J. R. Rao, M. P. Rajput and S. S. Yadav, Simultaneous quantitation of olmesartan medoxomil, amlodipine besylate and hydrochlorothiazide in pharmaceutical dosage form by using HPLC, Int. J. Pharm. Tech. Res. 3 (2011) 1435-1440.

13. J. Saminathan and T. Vetrichelvan, Method development and validation of olmesartan, amlodipine and hydrochlorothiazide in combined tablet dosage form, Int. J. Pharm. Res. Anal. 1 (2011) 7-14. 
14. H. Sharma, N. Jain and S. Jain, Development of spectrophotometric method for quantitative estimation of amlodipine besylate, olmesartan medoxomil and hydrochlorthiazide in tablet dosage form, Pharm. Anal. Acta 2 (2011) 1-4.

15. S. R. Patel and C. N. Patel, Development and validation of spectrophotometric method for determination of olmesartan, amlodipine and hydrochlorothiazide in combined pharmaceutical dosage forms, Novel Sci. Int. J. Pharm. Sci. 1 (2012) 317-321.

16. H. W. Darwish, Application of smart spectrophotometric methods and artificial neural network for the simultaneous quantitation of olmesartan medoxomil, amlodipine besylate and hydrochlorothiazide in their combined pharmaceutical dosage form, Chem. Cent. J. 7 (2013) 1-9; DOI: 10.1186/1752-153X-7-22.

17. H. W. Darwish, A. H. Bakheit and M. I. Attia, Three multivariate calibration methods for simultaneous spectrophotometric determination of olmesartan medoxamil, amlodipine besylate and hydrochlorothiazide in their combined dosage form, Dig. J. Nanomat. Biostr. 8 (2013) 323-333.

18. R. Tauler, Multivariate curve resolution applied to second order data, Chemometr. Intell. Lab. Syst. 30 (1995) 133-146; DOI: 10.1016/0169-7439(95)00047-X.

19. R. Gargallo, R. Tauler, F. Cuesta-Sanchez and D. Massart, Validation of alternating least-squares multivariate curve resolution for chromatographic resolution and quantitation, TrAC Trends Analyt. Chem. 15 (1996) 279-286. DOI: 10.1016/0165-9936(96)00048-9.

20. R. Kramer, Chemometric Techniques for Quantitative Analysis, CRC, New York 1998.

21. S. Wold, H. Antti, F. Lindgren and J. Öhman, Orthogonal signal correction of near-infrared spectra, Chemometr. Intell. Lab. Syst. 44 (1998) 175-185; DOI: 10.1016/S22. J. Sjöblom, O. Svensson, M. Josefson, H. Kullberg and S. Wold, An evaluation of orthogonal signal correction applied to calibration transfer of near infrared spectra, Chemometr. Intell. Lab. Syst. 44 (1998) 229-244; DOI: 10.1016/S0169-7439(98)00112-9.

23. T. Fearn, On orthogonal signal correction, Chemometr. Intell. Lab. Syst. 50 (2000) 47-52; DOI: 10.1016/ S0169-7439(99)00045-3.

24. J. A. Westerhuis, S. de Jong and A. K. Smilde, Direct orthogonal signal correction, Chemometr. Intell. Lab. Syst. 56 (2001) 13-25; DOI: 10.1016/S0169-7439(01)00102-2.

25. H. C. Goicoechea and A. C. Olivieri, A comparison of orthogonal signal correction and net analyte preprocessing methods. Theoretical and experimental study, Chemometr. Intell. Lab. Syst. 56 (2001) 73-81; DOI: 10.1016/S0169-7439(01)00110-1.

26. J. Jaumot, R. Gargallo, A. de Juan and R. Tauler, A graphical user-friendly interface for MCR-ALS: a new tool for multivariate curve resolution in MATLAB, Chemometr. Intell. Lab. Syst. 76 (2005) 101-110; DOI: 10.1016/j.chemolab.2004.12.007.

27. A. C. Olivieri, H. C. Goicoechea and F. A. Iñón, MVC1: an integrated MatLab toolbox for first-order multivariate calibration, Chemometr. Intell. Lab. Syst. 73 (2004) 189-197; DOI: 10.1016/j.chemolab.2004.03.004.

28. R. G. Brereton, Multilevel multifactor designs for multivariate calibration, Analyst 122 (1997) 15211529; DOI: 10.1039/A703654J.

29. D. M. Haaland and E. V. Thomas, Partial least-squares methods for spectral analyses. 1. Relation to other quantitative calibration methods and the extraction of qualitative information, Anal. Chem. 60 (1988) 1193-1202; DOI: 10.1021/ac00162a020. 